\title{
Obesity in adolescence-from etiological variability to interventional efficacy in the school context
}

\begin{abstract}
Introduction: Our paper concern two fundamental pillars to face obesity in adolescencenutrition education and the phenomenon of human variability, namely in the biological and behavior dimension.

Objectives: Assessment of the impact of an innovate school-based nutrition education program (OBESIDATA); the multivariate study of the anthropometric profile and physical activity pattern of adolescents in Portugal; comparison between energy consumption and their energy needs; Evaluation of the accuracy of four commonly used basal metabolic rate prediction equations

Results: After a two weeks period of open interactive digital platform, $85.8 \%$ of students increased their nutritional knowledge; the overall prevalence of overweight and obesity in adolescents was $16.5 \%$ and $5.9 \%$, respectively; just $38 \%$ of participants reported a level of physical activity in line with WHO recommendations; the RMR mean differences of six identified anthropometrics clusters vary from 1349 Kcalories to 1955 Kcalories; the mean reported energy intake was lower than the estimated energy requirements; from all predictive equations estimating energy requirements the relative accuracy, using indirect calorimetric evaluations, is just about $17 \%$.
\end{abstract}

Conclusions: School-based nutrition using technology may provide a practical, attractive and cost- effective strategy to improve nutrition knowledge and eating behaviors; the adolescent's prevalence of overweight/obesity remains relatively high and physical activity was clear below the WHO recommendations; at average level adolescents REI seems to be lower than their EER, but REI reveals a great individual variability; the accuracy of RMR using predictive equations may have limited applicability; a new paradigma to prevent obesity is coming where genetic will have soon a practical central role. ${ }^{1,2}$
Volume 9 Issue I - 2020

\author{
José M.Tallon, ${ }^{1,2}$ António J. Silva, ' Aldo M. \\ Costa, ${ }^{3}$ Ana Barros ${ }^{4}$ \\ 'Sports Sciences Department, Exercise and Health, University of \\ Trás-os-Montes e Alto Douro,Vila Real, Portugal \\ ${ }^{2}$ Medical Clinic Doctor Tallon \\ ${ }^{3}$ Sports Sciences Department, University of Beira interior, \\ Covilhã, Portugal \\ ${ }^{4}$ Centre for the Research and Technology of Agro-Environmental \\ and Biologicalsciences, University of Trás-os-Montes and Alto \\ Douro (UTAD-CITAB), 5000-80I Vila Real, Portugal
}

Correspondence: José M.Tallon, Sports Sciences Department, Exercise and Health, University of Trás-os-Montes e Alto Douro, Vila Real, Portugal, Email josemariatallon@clinicadrtallon.com

Received: February 21, 2020 | Published: March 06, 2020

Keywords: adolescence, nutrition education, energy requirements, obesity

Abbreviations: RMR, resting metabolic rate; PA, physical activity; BMI, body mass index; WHTR, waist-to-height ratio; REI, Reported Energy Intake; EER, estimated energy required

\section{Introduction}

Obesity, which has shown significant growth over the past half century, is now correctly considered to be one of the world's largest pandemics of the 21 st century. ${ }^{3}$ In fact, in the past 40 years, the world population has increased by about $80 \%$, having quintupled the number of obese adult women (465\%) from 69 million to 390 million, with an even greater increase in men (800\%), from 31 million to 281 million.

This trend has also been reported in children and adolescents and it is currently estimated that 170 million young people under 18 are obese, covering territories once relatively immune to high rates of overweight or obesity. ${ }^{4}$

As a result, over the last three decades, overweight and obesity have grown from 900 million to 2100 million.

Such diagnosis is inexorably reflected in the quality of life of contemporary society, being a risk factor for the development of several comorbidities, which, in the physical dimension, go beyond cardiovascular, osteoarticular or metabolic diseases because the inflammatory process resulting from obesity affects all organs and systems. ${ }^{5-7}$

Nor can we overlook the serious effects of obesity on mental health and social relationship of the subjects. On top of this is the continued increase in direct annual health care costs, paid by the individual or society in general, with spending on medicines growing by $77 \%$ and the number of medical consultations $35 \%$. Last but not least, the indirect costs, explained by the drop in productivity at work and the increase in absenteeism. ${ }^{8}$

Such considerations justify the attention that this problem has attracted to international organizations and particularly to the scientific, educational and health professional's community, in diverse areas of specialized knowledge. ${ }^{9}$

Our main research last years has explored two fundamental pillars in the study of obesity in adolescence - nutrition education, which plays a preventive role in seeking innovative solutions for youth awareness of healthy eating and the phenomenon of human variability, namely in the biological and behavioral dimension. 
The objectives of our investigation have fundamentally covered four areas of research:

i. evaluate the impact of using an interactive digital platform (Obesidata) to teach basic nutritional content to adolescents; ${ }^{10,11}$

ii. describe the anthropometric profile and physical activity pattern of adolescents, namely in Portugal; ${ }^{12}$

iii.compare the energy consumption of Portuguese adolescents/ young adults with their energy needs ${ }^{13}$ and

iv. determine the accuracy of four commonly used basal metabolic rate prediction equations. ${ }^{14}$

\section{Methods}

\section{Study sample and procedures}

In the context of first research area, an interactive digital platform with nutritional content ("Obesidata") was developed, which was made available to 1291 (Table 1) adolescents along 2 weeks for an autonomous study.

Table I Description of the sample: number of participants and percentages by gender, grade and school

\begin{tabular}{lll}
\hline & & N (\%) \\
\hline \multirow{3}{*}{ Gender } & Male & $584(45.2)$ \\
& Female & $707(54.8)$ \\
\hline \multirow{3}{*}{ Grade } & 9th & $255(19.8)$ \\
& I0th & $415(32.1)$ \\
& I th & $337(26.1)$ \\
& I2th & $284(22.0)$ \\
& A & $297(23.0)$ \\
& B & $326(25.3)$ \\
& C & $108(8.4)$ \\
& D & $35(2.7)$ \\
& E & $281(21.8)$ \\
& F & $244(18.9)$
\end{tabular}

The adolescents completed a knowledge questionnaire before and immediately after the intervention ended.

This platform, normally used in a Smartphone environment, allow us to record the responses to the first questionnaire and therefore the self-assessment of the initial knowledge in terms of nutrition, comparing it with classmates or from other classes at the School. It also allows access to the correct answers, as well as a synthetic and explanatory text of the inherent knowledge.

In the context of second research area a subsample of 946 adolescents (from 6 Portuguese schools) underwent a complete anthropometric assessment (age, sex, weight, height and waist circumference, body mass index (BMI), waist -height index, caloric basal needs and their level of physical activity (self-reported) through the help of the Physical Education Tutor. ${ }^{15,16}$

All this information was recorded on the OBESIDATA platform. The anthropometry measures details are available in Tallon JM. ${ }^{12}$ In the context of third research area, 286 adolescents of both sexes were recorded their food intake for at least 3 complete days. Food composition data was derived from the Portuguese Food Composition Table developed by the National Health Institute Doctor Ricardo Jorge. A complete anthropometric assessment and their energy requirements were calculated for comparison purposes ${ }^{17}$ using the Harris-Benedict equation. ${ }^{18}$ Finally, in the context of fourth research area a Basal metabolic rate ${ }^{19}$ was measured by indirect calorimetry in a sample of 156 women (age: $40.3 \pm 10.2$ years) recruited in the clinical setting.

The resulting values were compared ${ }^{20}$ with the predictive values of the Harris-Benedict, FAO/WHO/UNU, ${ }^{17}$ Schofield $^{21}$ and Mifflin-St $\mathrm{Jeor}^{22,23}$ equations in all BMI categories.

\section{Statistical analysis}

In the context of first research area data were analyzed using XLSTAT 2018. Summary statistics were obtained to characterize the statistical distribution of the nutrition knowledge scores at the baseline and post-intervention. T-tests were conducted to investigate the statistical significance of the evolution of knowledge along the learning process. Additionally a paired samples t-test was applied to compare the nutrition knowledge mean obtained at baseline and at post-intervention. In the context of second research area a univariate, bivariate and multivariate statistical analysis were developed.

In the context of third research area, we used parametric tests when the sample size was higher than 30 assuming that the sampling distribution of the mean was normal based on the Central Limit Theorem. To test the statistical differences between REI and EER means across age and gender categories an independent t-test was used. The one-way analysis of variance (ANOVA) was performed to determine whether there were statistical differences between REI and EER means across BMI categories and school grades. Effect size was estimated using Cohens'd indicator.

In the context of fourth research area a paired t-test or a Wilcoxon ranked test was developed to compare the differences between measured and estimated RMR. Prediction accuracy was defined as the percentage of individuals whose predicted RMR was between 90 and $110 \%$ of the measured RMR.

Last three areas data were analyzed using SPSS, version 24.0 (IBM Corp., Armonk,NY,USA).

\section{Results}

The results of our investigation have highlighted that after 2 weeks of open access to an interactive digital platform ("OBESIDATA"),85.8\% of students increased their nutritional knowledge, the global average increased, being of $32.3 \%$, (Table 2) more accentuated for younger students $(\mathrm{P}<0.001)$ and with a lower background level. The level of nutritional knowledge differed only between genders at the beginning of the intervention $(\mathrm{p}<0.001)$ (Table 3$)$. 
Table 2 Results of the pre-test and post-test ventilated by school

\begin{tabular}{|c|c|c|c|c|c|}
\hline & \multicolumn{2}{|c|}{ Baseline } & \multicolumn{2}{|c|}{ Post-intervention } & $\begin{array}{l}\text { Mean Evolution } \\
\%\end{array}$ \\
\hline School B & 35.2 & 9.6 & 46.7 & 15.6 & 32.7 \\
\hline School C & 30.6 & 8.1 & 46.0 & 18.4 & 50.3 \\
\hline School E & 38.6 & 12.0 & 51.1 & 16.9 & 32.2 \\
\hline School F & 38.5 & 10.4 & 50.8 & 14.5 & 31.9 \\
\hline TOTAL & 37.1 & 11.0 & 49.4 & 15.9 & 33.2 \\
\hline
\end{tabular}

M, mean; SD, standard deviation

Table 3 Initial and post-intervention nutrition knowledge scores regarding gender

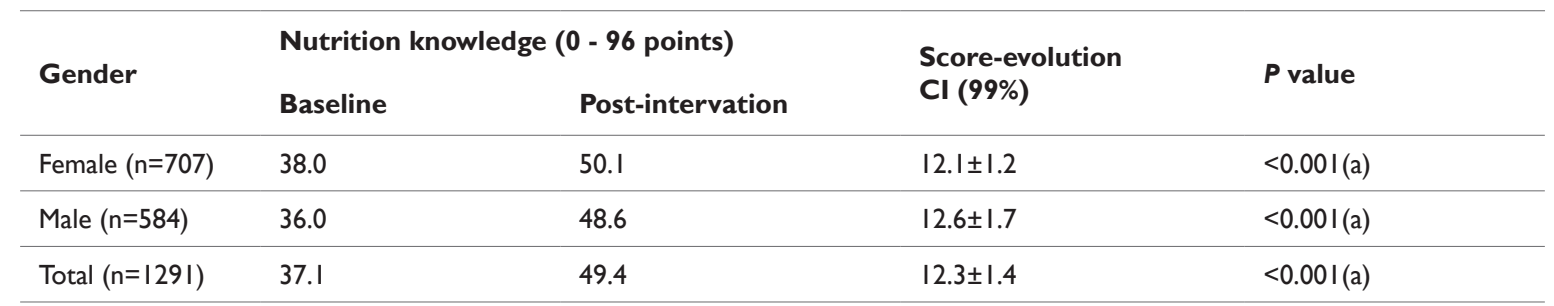

(a) Paired test

The overall prevalence of overweight and obesity in the sample was $16.5 \%$ and $5.9 \%$, respectively (Table 4 ). The difference in basal caloric needs (RMR) of the different groups identified by a cluster analysis $^{12}$ was from $1349 \mathrm{kcal}$. to $1955 \mathrm{kcal}$ (Table 5).

Table 4 Prevalence of overweight and obesity segregated by gender

\begin{tabular}{llll}
\hline & Overweight & Obese & Overweight/obese \\
\hline Girls $(n=535)$ & $62(11.6 \%)$ & $34(6.4 \%)$ & $96(18.0 \%)$ \\
\hline $\begin{array}{l}\text { Boys } \\
(n=4 I I)\end{array}$ & $38(9.3 \%)$ & $22(5.4 \%)$ & $60(14.6 \%)$ \\
\hline Total $(n=946)$ & $100(10.6 \%)$ & $56(5.9 \%)$ & $156(16.5 \%)$ \\
\hline
\end{tabular}

Results are expressed as number of individuals and (percentage)

Table 5 Gravity centers for the clusters

\begin{tabular}{llllll}
\hline Class & Weight & Height & BMI & WHtR & RMR \\
\hline Class I & 48.691 & 161.209 & 18.727 & 0.402 & 1349.777 \\
Class 2 & 59.655 & 173.333 & 19.882 & 0.418 & $159 \mid .447$ \\
Class 3 & 89.712 & $173.57 \mid$ & 29.845 & 0.550 & 1955.088 \\
Class 4 & 54.839 & 159.080 & 21.668 & 0.455 & 1396.334 \\
Class 5 & 67.621 & 162.314 & 25.694 & 0.504 & 1547.036 \\
Class 6 & 72.802 & 178.318 & 22.914 & 0.449 & 1827.550 \\
\hline
\end{tabular}

Citation: Tallon JM, Silva AJ, Costa AM, et al. Obesity in adolescence-from etiological variability to interventional efficacy in the school context. Biom Biostat Int J. 2020;9(I):22-26. DOI: 10.15406/bbij.2020.09.00296 
Table 6 Gravity centers for the clusters

\begin{tabular}{llllll}
\hline & Weight & Height & BMI & WHtR & RMR \\
\hline Girls & $30.0 \%$ & $40.8 \%$ & $21.2 \%$ & $7.1 \%$ & $1.0 \%$ \\
Boys & $23.3 \%$ & $26.6 \%$ & $26.8 \%$ & $20.8 \%$ & $2.5 \%$ \\
Total sample & $27.1 \%$ & $34.6 \%$ & $23.6 \%$ & $13.1 \%$ & $1.6 \%$ \\
\hline
\end{tabular}

The energy intake of adolescents/young adults (REI), measured by direct and instant registration on the OBESIDATA platform, was significantly lower than their estimated requirements (EER) for both genders, adolescents, normal weight, overweight and obese individuals and in all school grades $(\mathrm{P}<0.05)$. We found that this average difference was greater as the BMI increased, recording $117 \mathrm{kcal}$ in individuals with normal weight and $385 \mathrm{kcal}$ in the subgroup of obese individuals (Table 7).

Table 7 Mean and SD of EER and REl by BMI category

\begin{tabular}{llllll}
\hline & REI $(\mathrm{kcal})$ & EER $(\mathrm{kcal})$ & REI-EER $(\mathrm{kcal})$ & P-value & Cohen's d $\dagger$ \\
\hline BMI category & & & & & \\
\hline Underweight $(\mathrm{n}=7)$ & $1777.2 \pm 190.9$ & $1859.1 \pm 241.4$ & $-81.9 \pm 258.0$ & 0.433 & $-0.32 *$ \\
\hline Normal weight $(\mathrm{n}=237)$ & $1896.8 \pm 428.2$ & $2014.3 \pm 318.9$ & $-117.5 \pm 361.3$ & $<0.001$ & $-0.33^{*}$ \\
\hline Overweight $(\mathrm{n}=30)$ & $1912.5 \pm 385.2$ & $2214.1 \pm 320.5$ & $-301.6 \pm 294.1$ & $<0.001$ & $-1.03 * * *$ \\
\hline Obese $(\mathrm{n}=13)$ & $1964.1 \pm 290.2$ & $2362.2 \pm 233.8$ & $-398.1 \pm 185.7$ & $<0.001$ & $-2.14 * * *$ \\
\hline P-value & 0.811 & $<0.001$ & 0.002 & --- & -- \\
\hline
\end{tabular}

Individually, we found that adolescents who consumed more calories than their theoretical needs were of normal weight, overweight or underweight as well as teenagers who intake less than their theoretical needs were also distributed among the three weight classes.

The statistical evidence of these results challenges us to further reflection on the individual variability of caloric needs and questions us about how we use predictive equations.

The last considerations gave rise to a comparative study between the real caloric needs measured by indirect calorimetry and the theoretical needs obtained through four commonly used predictive equations. The results confirmed what we already suspected: at an individual level, the equations with the highest percentage of accurate predictions were the Mifflin-St. Jeor equation in normal weight women (41.9\%) and the Harris-Benedict equation in overweight (55.4\%) and obese $(50.9 \%)$ women (Table 8). And the Resting Metabolic Rate (RMR) took very different values in comparison with the theoretical needs, from $40 \%$ of these needs until $150 \%$.

Table 8 Comparison of RMR values from IC and the selected prediction equations for overweight women $(n=56)$.

\begin{tabular}{|c|c|c|c|c|c|c|c|}
\hline & $\begin{array}{l}\text { RMR } \\
\text { (Mean } \pm S D, \\
\text { kcal/day) }\end{array}$ & P-value & $\begin{array}{l}\text { Accurate } \\
\text { prediction* } \\
\text { [n (\%)] }\end{array}$ & $\begin{array}{l}\text { Under } \\
\text { prediction } \dagger \\
{[n(\%)]}\end{array}$ & $\begin{array}{l}\text { Over } \\
\text { prediction } \ddagger \\
{[n,(\%)]}\end{array}$ & $\begin{array}{l}\text { Absolute } \\
\text { error } \\
\text { (Mean, } \\
\text { kcal/day) }\end{array}$ & $\begin{array}{l}\text { Relative } \\
\text { error } \\
\text { (Mean, } \\
\%)\end{array}$ \\
\hline $\begin{array}{l}\text { Indirect } \\
\text { Calorimetry }\end{array}$ & $\begin{array}{l}1391.4 \pm \\
268.9\end{array}$ & --- & --- & --- & --- & --- & ---- \\
\hline Harris-Benedict & | $448 . \mid \pm 98.4$ & 0.112 & $31(55.4)$ & $8(14.3)$ & I7(30.4) & 191.7 & 17.0 \\
\hline Schofield [weight] & | $443.5 \pm 87.2$ & 0.140 & $29(51.8)$ & $8(14.3)$ & $19(33.9)$ & 192.7 & 17.0 \\
\hline FAO/WHO/UNU & | $463.4 \pm 80.8$ & 0.043 & $29(51.8)$ & $8(14.3)$ & 19(33.9) & 192.7 & 17.2 \\
\hline Mifflin-St. Jeor & $\begin{array}{l}\text { I } 364.2 \pm \\
\text { I } 28.0\end{array}$ & 0.138 & $23(4 I . I)$ & $19(33.9)$ & $14(25.0)$ & 208.6 & 17.4 \\
\hline
\end{tabular}

RMR, resting metabolic rate; * Number and percentage of individuals whose predicted RMR was between 90 and II0\% of the measured RMR; $\dagger$ Number and percentage of individuals whose predicted RMR was $90 \%$ of the measured RMR; $\ddagger$ Number and percentage of individuals whose predicted RMR was $>$ I I $0 \%$ of the measured RMR 


\section{Conclusions and future developments}

School-based interventions, particularly with technology support, appear to be a valid tool for nutrition education and healthy lifestyles for adolescents.

Gender and background knowledge seem to influence the learning process, which should be considered when designing future interventions. Our results also showed that the prevalence of overweight / obesity in the evaluated adolescents is relevant (16.5\%), with only a little over one third (38\%) being physically active.

We also conclude that, in general, the energy intake of adolescents / young adults seems to be lower than their theoretical energy requirements, but that there is a great individual variability. Finally, we concluded that the accuracy of the resting metabolic rate prediction equations studied varied by weight status and might have limited applicability for Portuguese women at an individual level. Human beings are much more complex than simple mathematical equations- we are chemically and biologically different and we have different needs, which explain the enormous difficulty for the treatment and control of obesity.

In our perspective, we will have to give priority to two basic pillars of action:

\section{Behavior pillar}

a. Increase knowledge of nutrients and of real needs of our body so that we can make the right choices in terms of food.

b. Encourage the practice of physical activity.

II. Biochemical/Genetic pillar

Advances in the Biochemical and Biological study of organism in order to better understand the mechanisms of appetite, satiety, absorption, metabolization and elimination of nutrients and how to control them.

The field of Genetics will be, without any doubt, the one that will allow a great advance in the knowledge and control of problems related to overweight and obesity.

\section{Funding}

This research was funded by National Funds by FCT-Portuguese Foundation for science and Technology, under the project UIDB/04033/2020.

\section{Conflicts of interest}

Authors declare that there is no conflicts of interest

\section{Acknowledgments}

None.

\section{References}

1. Nirmala A, Reddy BM, Reddy PP, et al. Genetics of Human Obesity: An Overview. International Journal of Humam Genetics. 2008;8(1-2):217226.

2. Xia Q, Grant SFA. The genetics of Human Obesity. Ann NY Acad Sci. 2013;1281:178-190.

3. Ng M, Fleming T, Robinson M, et al. Global, Regional and National Prevalence of Overweight and Obesity in Children and Adults During 1980-2013: A Systematic Analysis for the Global Burden of Disease Study 2013. Lancet. 2014;384(9945):766-781.
4. Abarca- Gómez, Abdeen ZA, Hamid ZA, et al. Worldwide Trends in Body -Mass Index, Underweight, Overweight and Obesity from 1975 to 2016: A Pooled Analysis of 2416 Population-Based Measurement Studies in 128.9 Million Chidren, Adolescents and Adults. Lancet. 2017;390(10113):2627-2642.

5. Apovian CM. Obesity: Definition,Comorbidities, Causes and Burden. Am J Manag Care. 2016;22(7):s176-s185.

6. Gadle KM, Martin CK, Berthoud HR, et al. Obesity: Pathophysiology and Management. J Am Coll Cardiol. 2018;71(1):69-84.

7. Jarolimova J, Tagoni J, Stern TA. Obesity: its Epidemiology, Comorbidities, and Management. Prim Care Companion CNS Disord. 2013:15(5)

8. Dee A, Kearns K, O'Neill C, et al. The Direct and Indirect Costs of Body Overweight and Obesity: A Systematic Review. BMC Res Notes. 2014;7:242.

9. Tallon JM, Narciso J, Barros A, et al. Obesity: nutrition and genetics- a short narrative review. Health. 2018;10(12):1779-1788.

10. Tallon JM, Dias RS, Costa AM, et al. Impact of Technology and SchoolBased Nutrition Education Programs on Nutrition Knowledge and Behavior During Adolescence-A Systematic Review. Scandinavian Journal of Educational Research. 2019;1-12.

11. Tallon JM, Saavedra Dias R, Costa AM, et al. Pilot Evaluation of an Interactive Multimedia Platform to Provide Nutrition Education to Portuguese Adolescents. European Journal of Public Health. 2019.

12. Tallon JM, Saavedra Dias R, Silva AJ, et al. Characterization of the anthropometric profile and physical activity levels of Portuguese adolescents. Biometrics \& Biostatistics International Journal. 2019;8(5):184-193.

13. Tallon JM, Narciso J, Saavedra Dias R, et al. Reported energy intake versus estimated energy requirements of portuguese adolescents and young adults. Progress in Nutrition. 2020;22(3):1-9.

14. Tallon JM, Narciso J, Saavedra Dias R, et al. Comparison of predictive equations for resting metabolic rate in Portuguese women in Motricidade. 2019.

15. Physical Status. The use and interpretation of anthropometry. Tecnical Report Series number 854. 1995.

16. World Health Organization(WHO). Physical activity and young people. 2015 .

17. FAO/WHO/UU University. Energy and Proteins requirements. WHO Technical Report Series, Geneva. 1985:724.

18. Arthur Harris BJ, Benedict FG. A Biometric Study of Human Basal Metabolism. USA: Proc Natl Acad Sci. 1918;4(12):233-236.

19. Nhung BT, Khan NC, Hop LT, et al. FAO/WHO /UNU equations overestimate resting metabolic rate in Vietnamese adults. Eur J Clin Nutr. 2005;59(10):1099-1104.

20. Krüger RL, André Luiz Lopes, Júlia da Silveira Gross, et al. Validação de equações de predição da taxa metabólica basal em sujeitos eutróficos e obesos. Revista Brasileira Cineantropometria e Desempenho humano. 2014;17(1):73.

21. Shofield WN. Predicting basal metabolic rate, new standards and review of previous work. Hum Nutr Clin Nutr. 1985;39(1):5-41.

22. Mifflin MD, St Jeor ST, Hill LA, et al. A new predictive equation for resting energy expenditure in healthy individuals. Am J Clin Nutr. 1990;51(2):241-247.

23. Omoleke SA. Obesity: A major public health challenge of the 21st century in the United Kingdom (UK). Journal of Public Health and Epidemiology. 2011;3(12):560-566. 